are involved in the processes of coagulation, inflammation, immune response and wound repair, have been localised to chromosome bands $4 \mathrm{q} 12-\mathrm{q} 13 .^{9}$ It is intriguing to speculate that this constitutional genetic abnormality may have not only contributed to this patient's myelofibrosis by affecting PDGF production, ${ }^{10}$ but that it may have played a role in the development of his lymphoma and the pattern of his repeated septic episodes. The patient's atypical course and response to therapy may therefore reflect an unusual pattern of a rare disease modified by an unique underlying constitutional chromosomal aberration.

\section{Addendum}

Since the original submission of this article, a report has appeared of a non-constitutional $(3 ; 4)$ translocation occurring in association with a myeloproliferative disorder. (Myint $\mathrm{H}$, Chacko J, Mould S, Ross F, Oscier DG. Karyotypic evolution in a granulocytic sarcoma developing in a myeloproliferative disorder with a novel (3;4) translocation. BrF Haematol 1995; 90:462-4.)
1 Kinney MC, Collins RD, Greer JP, Whitlock JA, Sioutos N, Kadin ME. A small-cell-predominant variant of primN, Kadin ME. A small-cell-predominant variant of primary $\mathrm{Ki}-1(\mathrm{CD} 30+)$

2 Bitter MA, Franklin WA, Larson RA, McKeithan TW, Rubin CM, Le Beau MM, et al. Morphology in $\mathrm{Ki}-1$ (CD30)-positive non-Hodgkin's lymphoma is correlated with clinical features and the presence of a unique chromosomal abnormality, t $(2 ; 5)(\mathrm{p} 23 ; \mathrm{q} 35)$. Am 7 Surg Pathol 1990;14:305-16.

3 Le Beau MM, Bitter MA, Larson RA, Doane LA, Ellis ED, Franklin WA, et al. The $t(2 ; 5)(\mathrm{p} 23: \mathrm{q} 35)$ : a recurring chromosomal abnormality in $\mathrm{Ki}-1$ positive anaplastic large cell lymphoma. Leukemia 1989;3:866-70.

4 Epstein RJ, Joshua DE, Kronenberg H. Idiopathic myelofibrosis complicated by lymphoma. Report of two cases. Acta Haematol 1985;73:40-4.

5 Jennings WH, Li CY, Kiely JM. Concomitant myelofibrosis with agnogenic myeloid metaplasia and malignant lymphwith agnogenic myeloid metaplasia and

6 Wong KF, Chan JK, Ng CS, Chu YC, Lam PW, Yuen HL. Anaplastic large cell $\mathrm{Ki}-1$ lymphoma involving bone marrow: Marrow findings and association with reactive haemophagocytosis. Am f Hematol 1991;37:112-19.

7 Chott A, Kaserer K, Augustin I, Vesely M, Heinz R, Oehlinger $\mathrm{W}$, et al. $\mathrm{Ki}-1$-positive large cell lymphoma. A clinicopathologic study of 41 cases. Am $\mathcal{F}$ Surg Pathol 1990;14:439-48.

8 Andre C, Martin E, Cornu F, Hu WX, Wang XP, Galibert F. Genomic organization of the human c-kit oncogene: evolution of the receptor tyrosine kinase subclass III Oncogene 1992;7:685-91.

9 Tunnacliffe A, Majumdar S, Yan B, Poncz M. Genes for beta-thromboglobin and platelet factor 4 are closely linked and form part of a cluster of related genes on chromosome 4. Blood 1992;79:2896-900.

10 Reilly JT. Pathogenesis of idiopathic myelofibrosis: Role of growth factors. $f$ Clin Pathol 1992;45:461-4.

\title{
Langerhans cell histiocytosis forming an asymptomatic solitary nodule in the spleen
}

\section{Department of Pathology, Queen Mary Hospital, Hong Kong K Y Lam \\ A C L Chan}

\section{Department of}

Medicine

M S Wa

\section{Correspondence to:}

Dr K Y Lam, Department

of Pathology, Queen Mary

Hospital, Pokfulam Road,

Hong Kong.

Accepted for publication 18 October 1995

\begin{abstract}
A case of solitary Langerhans cell histiocytosis (LCH) in the spleen of a 29 year old Chinese man, discovered incidentally at necropsy, is reported. This is the first
\end{abstract}

documented case of $\mathrm{LCH}$ confined to the spleen and suggests that LCH should be included in the differential diagnosis of space occupying lesions in the spleen.

(f Clin Pathol 1996;49:262-264)

Keywords: Langerhans cell histiocytosis, spleen.

The common denominator of all forms of Langerhans cell histiocytosis (LCH), formerly known as histiocytosis $\mathrm{X}$, is the presence of histiocytes phenotypically similar to the Langerhans cell of the epidermis. The disease has a wide range of clinical and pathological presentations. Almost every organ in the body can be involved in $\mathrm{LCH}$, the favoured sites being the skin, bone, lungs, and lymph nodes. ${ }^{1}$ While splenic infiltration is part of the multisystem disease in LCH, histiocytosis confined to the spleen, to our knowledge, has never been documented in the literature.

\section{Case report}

An otherwise healthy 29 year old Chinese man developed sudden onset retrosternal chest pain, shortness of breath and sweating. He then de-
Figure 1 A slice of the sectioned spleen showing a white nodule (arrow) underneath the splenic capsule. 


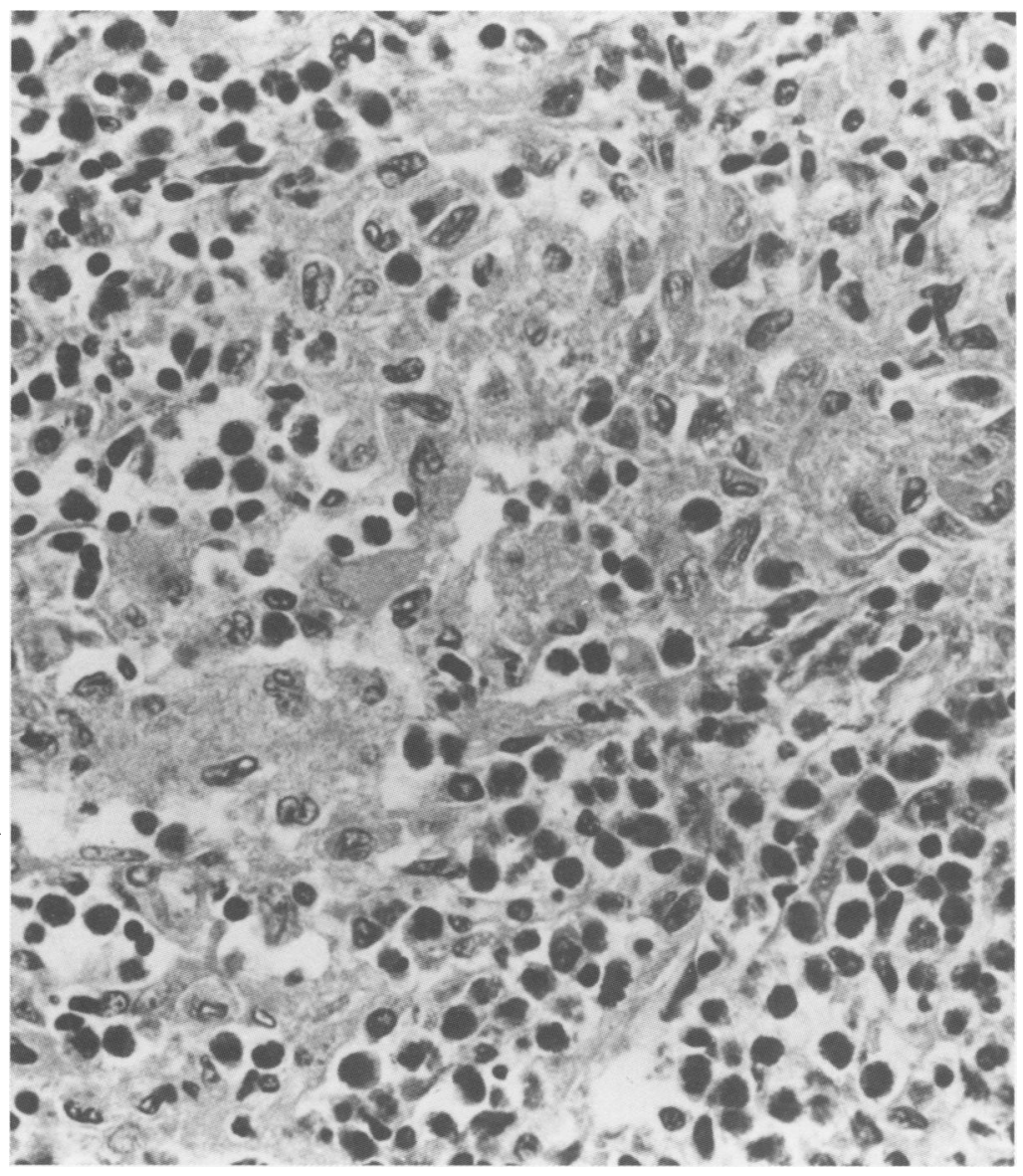

Figure 2 Langerhans cell histiocytosis showing the characteristic aggregates of Langerhans histiocytes with grooved nuclei admixed with eosinophils. (Haematoxylin and eosin; original magnification $\times 500$.)

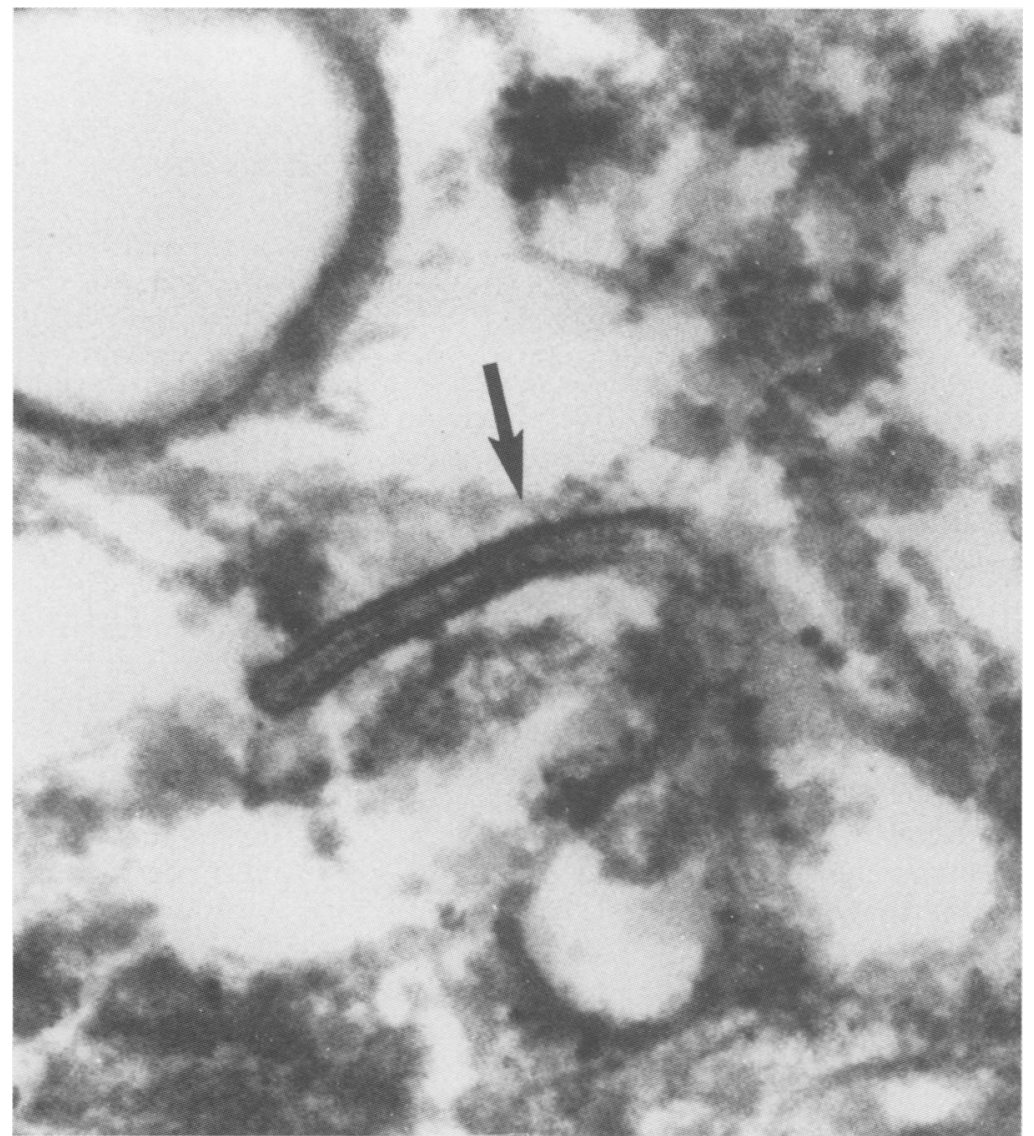

Figure 3 Electron microscopic examination of one of the tumour cells in the splenic nodule showing the Birbeck granule (arrow): a rod-shaped structure with a striated, zipper-like core in the cytoplasm of a Langerhans cell. (Uranyl acetate, lead acetate; original magnification $\times 120000$.) veloped cardiorespiratory arrest and was certified dead two hours after admission to hospital.

At necropsy, the cause of death was ischaemic heart disease and the lumen of the anterior descending branch of the left coronary artery was $95 \%$ narrowed by an atheroma. On gross examination of the spleen, a whitish nodule, measuring $0.7 \mathrm{~cm}$ in diameter, was noted in the splenic parenchyma underneath the capsule (fig 1). It was well demarcated, but not encapsulated. The rest of the splenic parenchyma appeared unremarkable.

\section{MICROSCOPIC FINDINGS}

Microscopic examination of the nodule revealed that it was composed of numerous eosinophils and aggregates of cells with folded nuclei, delicate chromatin, inconspicuous nucleoli, and abundant eosinophilic cytoplasm characteristic of Langerhans cells (fig 2). Occasional multinucleated giant cells were also present. The cells were strongly immunoreactive for S-100 protein (diluted 1 in 200, polyclonal; Dako, Glostrup, Denmark). Fresh tissue was not available for immunostaining with antibody directed against CD1. The tumour tissue was suboptimal for ultrastructural examination as it was taken at necropsy and had not been prefixed in glutaraldehyde. However, in tissue post-fixed with osmium the histiocytic cells had the characteristic morphology of Langerhans cells with numerous cell processes and Birbeck granules (fig 3). The diagnosis of this splenic lesion as $\mathrm{LCH}$ was thus confirmed. No other similar lesions were identified elsewhere in the body.

\section{Discussion}

$\mathrm{LCH}$ can be seen at any age, ranging from birth to old age, with a peak between one and three years. ${ }^{2}$ In very young children the disease is usually multifocal with profound constitutional symptoms and occasionally organ failure. In older children and adults the disease is usually confined to a single organ which may spontaneously regress or require minimal treatment. The disease is characterised by aggregates of Langerhans histiocytes admixed with eosinophils. Langerhans cells possess grooved nuclei and show positive immunostaining with antibody directed against S-100. Ideally, the diagnosis of $\mathrm{LCH}$ should be confirmed by the presence of Birbeck granules on ultrastructural examination and immunoreactivity of the cells in frozen sections for the marker CD1. However, in most instances, the diagnosis can be made on the characteristic morphology of the cells seen in routine sections.

In most patients with the solitary form of the disease, $\mathrm{LCH}$ involves bone. However, LCH confined to the skin, lymph nodes, lungs, or even thyroid has also been reported. ${ }^{1-3}$ The present case documents the extremely rare occurrence of $\mathrm{LCH}$ apparently confined to the spleen, which was an incidental finding on necropsy. In this case multisystem involvement, 
although unlikely, could not be completely excluded as there might have been occult bony lesions.

The pathogenesis and nature of $\mathrm{LCH}$ are not clearly understood; viruses and cytokines have been proposed as aetiological agents for the abnormal proliferation of the Langerhans cells. ${ }^{4}$ However, there is no conclusive evidence to support these hypotheses. There is also debate whether $\mathrm{LCH}$ is a reactive or neoplastic lesion. Many LCH lesions, as in the present report, are asymptomatic, solitary and nonprogressive. The occasional association of $\mathrm{LCH}$ with malignant neoplasms and inflammatory processes suggest that LCH may develop as an unusual host reaction to these diseases. To date, genetic abnormalities have not been detected in $\mathrm{LCH}$. All these findings support the view that $\mathrm{LCH}$ is a reactive condition. However, the aggressive nature of systemic LCH and the demonstration of monoclonality in some cases suggest that the disease may be neoplastic in nature. ${ }^{5}$ In this context it is worth noting that monoclonality does not confirm the existence of malignancy; clonality alone does not predict the behaviour of LCH.

Splenic infiltration by systemic $\mathrm{LCH}$ is usually discovered at necropsy and is char- acterised by a diffuse splenic red pulp infiltration by Langerhans cells. In such cases of splenic involvement, patients may present with fatal thrombocytopenia because of hypersplenism. Indeed, splenomegaly is a poor prognostic factor in patients with LCH. Splenic rupture has also been reported. ${ }^{6}$ In contrast, the splenic lesion in this case was solitary, small and asymptomatic, and would probably have been self-limiting. The present case is the first to be reported of solitary LCH in the spleen. As occult $\mathrm{LCH}$ is almost certainly underdiagnosed in adults, we await reports of similar cases in future.

1 Henry K. Lymph nodes, Langerhans cell histiocytosis. In: Henry $\mathrm{K}$, Symmers WStC, eds. Systemic pathology. Vol 7. Thymus, lymph nodes, spleen and lymphatics. 3rd edn. 7. Thymus, lymph nodes, spleen and lymphatics. 3rd

2 Broadbent V, Egeler RM, Nesbit ME. Langerhans cell histiocytosis: clinical and epidemiological aspects. $\mathrm{Br} \mathcal{F}$ Cancer 1994;70:S11-16.

3 Tsang WYW, Lau MF, Chan JKC. Incidental Langerhans' cell histiocytosis of the thyroid. Histopathology 1994;24: 397-9.

4 McClain $\mathrm{K}$, Weiss RA. Viruses and Langerhans cell histiocytosis: Is there a link? $B r \mathcal{F}$ Cancer 1994;70:S34-6.

5 Willman CL. Detection of clonal histiocytes in Langerhans cell histiocytosis: biology and clinical significance. $\mathrm{Br} f$ Cancer 1994;70:S29-33.

6 Broadbent V, Williams M, Dossetor J. Ruptured spleen as a cause of death in an infant with Langerhans cell histiocytosis (histiocytosis X). Pediatr Hematol Oncol 1990;7:297-9.

\title{
Lymphocyte infiltration in oesophageal carcinoma: lack of correlation with $\mathrm{MHC}$ antigens, ICAM-1, and tumour stage and grade
}

\author{
J C Rockett, S J Darnton, J Crocker, H R Matthews, A G Morris
}

\author{
Clinical Sciences \\ Laboratory, \\ Department of \\ Biological Sciences, \\ University of Warwick, \\ Coventry CV4 7AI \\ J C Rockett \\ A G Morris \\ Department of \\ Thoracic Surgery, \\ Birmingham \\ Heartlands Hospital, \\ Birmingham B9 $5 S S$ \\ $S$ J Darnton \\ H R Matthews \\ Department of \\ Histopathology \\ J Crocker \\ Correspondence to: \\ Dr S J Darnton. \\ Accepted for publication \\ 21 November 1995
}

\begin{abstract}
Infiltration by $\mathbf{T}$ lymphocytes into oesophageal carcinomas was assessed immunohistochemically, total T lymphocyte numbers by staining for $\mathrm{CD} 3$ and activated $\mathrm{T}$ lymphocytes by staining for CD25. Five squamous carcinomas and seven adenocarcinomas, resected without neoadjuvant treatment, were studied. Computer aided quantitation showed that total numbers of tumour infiltrating CD3 positive cells were highly variable (range $48-1673 \mathrm{cells} / \mathrm{mm}^{2}$ ). They were located largely in the stromal $(87 \cdot 9-99 \cdot 2 \%)$ rather than intratumoral regions. Up to $84 \%$ of tumour infiltrating $T$ lymphocytes were CD25 positive, although the median figure was $33 \%$. There was no correlation between $T$ lymphocyte infiltration or activation and expression of class I and II histocompatibility antigens, intercellular adhesion molecule-1, tumour stage or grade. These results imply that the local inflammatory response in oesophageal carcinomas is deregulated, which
\end{abstract}

may be a factor contributing to the aggressive nature of the tumours. (f Clin Pathol 1996;49:264-267)

Keywords: ICAM-1, lymphocyte infiltration, MHC, oesophageal carcinoma

Cancer of the oesophagus is an aggressive malignancy with a high mortality rate. The two primary types of this neoplasm, namely adenocarcinoma and squamous cell carcinoma, have overall five year survival rates of only 0.8 and $6.3 \%$, respectively. ${ }^{1}$ One reason for such poor survival could be the failure of the host immune system to recognise and eliminate the neoplastic cells.

Paul Ehrlich originally postulated that a tumour may be recognised as antigenically foreign by the host. This concept was later refined into the theory of immunological surveillance against cancer. Evidence cited in favour of the theory includes the accumulation of lymphocytes at most tumour sites. The extent of such lymphoid infiltrations has been assessed in various tumours, and has in many instances 